\title{
Influenza Aviar y Riesgo de Pandemia
}

\author{
CECILIA PERRET P. ${ }^{1}$, JEANNETTE DABANCH P. ${ }^{2}$ \\ 1. Departamento de Pediatría, Pontificia Universidad Católica de Chile. \\ 2. Departamento de Medicina Interna, Hospital Militar.
}

\begin{abstract}
Pandemic risk of Avian Influenza

Influenza is a common season pathology that occasionally presents pandemia, caused by a new Influenza A virus subtype that results from the genomic recombination of human virus with virus from other species. During the last years, there is a worldwide alert situation in terms of a new pandemia, due to the existence of Influenza A virus subtype H5N1 in birds from Southeast Asia, Europe and Africa. There are some sporadic cases in humans produced by close exposure with infected birds. The present article reviews the virologic characteristics of Influenza A H5N1 virus in humans and the chilean guidelines for a potential pandemia. Influenza is a respiratory disease produced by Influenza virus A,B,C, being the A type the most important due to its capacity to change structure and cause epidemia or pandemia. The last pandemias were classified as Spanish flu in 1918-1919 (H1N1), Asian flu in 1957 (H2N2) and the Hong-Kong flu in 1967 (H3N2), with the biggest death population in 1918. In template countries, Influenza presents in epidemia affecting the winter months; in tropical countries, the virus circulation occurs during the whole year.

(Key words: Influenza, avian, pandemia, virus)

Rev Chil Pediatr 2008; 79 (4): 358-363
\end{abstract}

\section{RESUMEN}

Influenza es una enfermedad común que se presenta en Chile en forma estacional. Ocasionalmente ocurren pandemias las que se generan cuando aparece un nuevo subtipo de virus influenza A en la humanidad producto de la recombinación de genomas de virus de influenza humano con virus de influenza de otras especies. En los últimos años la humanidad se encuentra en una situación de alerta de una nueva pandemia dada la existencia de la más grande epizootia por influenza A, subtipo H5N1 en aves que se extiende desde el Sudeste Asiático a Europa Oriental, Occidental y África. Se han documentado casos esporádicos en humanos por contacto cercano con aves infectadas. El presente artículo revisa las características virológicas del virus de influenza A, la situación actual de la epizootia por $\mathrm{H} 5 \mathrm{N1}$, las características de esta infección en humanos y el estado de preparación que se encuentra Chile frente a una eventual pandemia.

(Palabras clave: Influenza, aviar, pandemia, virus).

Rev Chil Pediatr 2008; 79 (4): 358-363

Trabajo recibido el 01 de agosto de 2008.

Correspondencia a:

Cecilia Perret $P$.

E-mail: cperret@med.puc.cl 
Influenza es una enfermedad respiratoria que afecta a la humanidad desde tiempos remotos. Es producida por virus influenza A, B y $\mathrm{C}$ siendo el virus de influenza A el más importante dada su capacidad de variar en su estructura y causar brotes epidémicos periódicos o pandemias. Las ultimas pandemias han sido la de 1918-1919 (H1N1) llamada la gripe española; la influenza asiática en 1957 (H2N2) y la influenza de Hong-Kong en 1967 (H3N2) siendo la de 1918 la que registró un mayor número de muertos ${ }^{1,2}$.

En los países templados característicamente los brotes de influenza son estacionales y se presentan durante el período invernal, mientras que en los países con climas tropicales la circulación de este virus ocurre durante todo el año.

\section{Características virológicas}

El virus influenza es un virus ARN con envoltura que pertenece a la familia Orthomyxoviridae y se clasifica en tres tipos diferentes de acuerdo a su reactividad serológica: A, B y C siendo los dos últimos causantes de enfermedad solamente en el hombre mientras que influenza A causa enfermedad en una variedad de especies y posee un reservorio muy amplio principalmente en las aves silvestres. El virus influenza tiene dos proteínas estructurales en su envoltura que en el caso del virus influenza A son muy importantes en la patogenia y variación del virus. Estas son la hemaglutinina $(\mathrm{H})$ y la neuroaminidasa $(\mathrm{N})$ que de acuerdo a sus variaciones se describen distintos subtipos. Existen 16 subtipos de hemaglutinina $(\mathrm{Hl}$ a $\mathrm{H} 16)$ y 9 subtipos de neuroaminidasa ( 11 a N9) ${ }^{3}$. En la naturaleza todos estos subtipos están representados en el reservorio principal, que son las aves silvestres, mientras que en el hombre sólo existen 3 subtipos de hemaglutininas $(\mathrm{H} 1, \mathrm{H} 2$, H3) y dos subtipos de neuroaminidasas (N1, N2) dando origen a las cepas que circulan actualmente $\mathrm{H} 1 \mathrm{~N} 1$ y H3N2. La cepa H2N2 fue la causante de la influenza asiática en 1957 pero actualmente no circula.

La capacidad de variar del virus influenza A radica en dos factores importantes, la fragmentación en 8 segmentos de su genoma, lo que favorece el intercambio genético entre ellos y las fallas en la RNA polimerasa cuya fidelidad en la lectura no es buena, generándose numerosos errores en la transcripción, los que se traducen en cambios de aminoácidos en las proteínas que se sintetizan. Las variaciones pueden ser de dos tipos: el drift antigénico en que se producen cambios pequeños en estas proteínas sin constituir un nuevo subtipo y el shift antigénico donde ocurren cambios mayores generándose una proteína completamente nueva, es decir un nuevo subtipo ${ }^{3,4}$. Los cambios menores o drift se producen por mutaciones puntuales en las proteínas de la hemaglutinina o neuroaminidasa que generan una evasión parcial de la respuesta inmune y son los responsables de los brotes anuales de influenza. El shift antigénico se produce por el reordenamiento del genoma viral entre dos virus de influenza $\mathrm{A}$ de distintas especies cuando co-infectan a un mismo individuo, generando la aparición de un nuevo subtipo por lo que el sistema inmune lo desconoce completamente quedando toda la humanidad susceptible a enfermar ${ }^{5}$. Las pandemias de 1957 y 1968 fueron ocasionadas por nuevos subtipos de influenza A, H2N2 y H3N2 respectivamente, los cuales fueron generados por el mecanismo del shift antigénico, es decir por el reordenamiento genético entre virus de influenza A de distintas especies, un virus $\mathrm{H} 2 \mathrm{~N} 2$ aviar con H1N1 humano para el caso la pandemia de 1957, y el reemplazo de $\mathrm{H} 2$ humano por $\mathrm{H} 3$ proveniente de un virus aviar en el caso del virus de la pandemia de 1968. La pandemia de la gripe española, sin embargo, en 1918 fue ocasionada por cambios sucesivos de un virus de influenza aviar H1N1 hasta que adquirió la capacidad de adaptarse y hacerse transmisible entre los seres humanos ${ }^{6}$.

El virus de influenza A tiene especificidad por especie. Esta especificidad está determinada por la unión de la hemaglutinina (dependiente de su configuración) al receptor de ácido siálico en el tracto respiratorio de las diferentes especies. Así el virus de influenza A humano es capaz de infectar efectivamente al hombre por tener la configuración a 2,6 galactosa de la hemaglutinina capaz de unirse al receptor humano en cambio el de influenza aviar es capaz de infectar a las aves por tener la configuración 
a 2,3 galactosa específica para receptores avia$\mathrm{res}^{7}$. Un virus de influenza aviar no es fácilmente trasmisible entre los hombres y viceversa. Los cerdos, un reservorio importante, son la excepción pues tienen receptores tanto para virus de influenza aviar como de influenza humana además de influenza porcina. Esto los transforma en sujetos importantes en la generación de nuevos subtipos al tener la potencialidad de co-existir en ellos virus de distintas especies $^{8}$.

\section{Influenza aviar}

El virus influenza A puede afectar a muchas especies, entre otros caballos, ballenas, focas, cerdos y aves. Las aves acuáticas representan el mayor reservorio para este virus y juegan un rol preponderante en la cadena de transmisión de éste, con diseminación a otras aves y animales acuáticos. En las aves silvestres, influenza A suele producir una infección leve o asintomática y sólo ocasionalmente produce enfermedad con alta mortalidad especialmente cuando compromete a las aves de co$\mathrm{rral}^{9}$. La influenza aviar fue documentada por primera vez en 1878 y su agente etiológico fue identificado en 1955. Es producida por el virus de influenza A. Desde el siglo pasado se han identificado más de 20 brotes (epizootias) de influenza aviar en el mundo los que han sido producidos principalmente por los subtipo de hemaglutinina $\mathrm{H} 5, \mathrm{H} 7, \mathrm{H} 9$ y de neuroaminidasa $\mathrm{N} 1, \mathrm{~N} 2, \mathrm{~N} 3, \mathrm{~N} 7$ y N9. En algunos de estos brotes se ha documentado trasmisión accidental hacia el hombre produciéndose casos esporádicos debido a la incapacidad de estas cepas de adaptarse a este hospedero accidental. Según su virulencia los virus de influenza aviar se clasifican como de alta patogenicidad (H5, H7, H9) causando enfermedad grave entre las aves, especialmente en las aves de corral, o de baja patogenicidad.

En Chile se ha identificado y caracterizado sólo un brote de influenza aviar el cual ocurrió en dos criaderos de aves de corral en la provincia de San Antonio en el año 2002. Fue producida por el subtipo H7N3 y afectó tanto a gallinas reproductoras como a pavos. Para su adecuado control se sacrificaron casi medio millón de aves y no se registraron casos en humanos ${ }^{10}$.

\section{Epizootia por H5N1}

El brote de influenza aviar por la cepa $\mathrm{H} 5 \mathrm{~N} 1$ que hoy preocupa a la humanidad está afectando aves silvestres y aves de corral actualmente en alrededor de 48 países.

Esta cepa, de alta patogenicidad, apareció por primera vez en Hong Kong en 1997 afectando a miles de aves y fue necesario el sacrificio de dos millones para su control. Se detectaron en esa oportunidad 18 casos en humanos con muerte en 6 de ellos. Desde esa fecha no se volvió a detectar hasta el año 2003 cuando aparece nuevamente en aves de corral del Sudeste Asiático. Desde entonces y a pesar de las medidas de control aplicadas que comprende el sacrificio de millones de aves no se ha logrado contener. Hasta la fecha y desde el año 2003 se han visto afectados 61 países con casos de influenza aviar en aves silvestres o de corral, propagándose hacia Europa oriental, occidental y África (figura 1). Se estima que unas de las formas de diseminación más importante han sido las aves migratorias por lo que podría esperarse la aparición de focos en otras áreas geográficas.

\section{Influenza aviar en humanos}

La transmisión a humanos ha sido ocasional registrándose casos en 15 países, Tailandia, Vietnam, Camboya, China, Indonesia, Laos, Myanmar, Turquía, Egipto, Nigeria, Pakistán, Irak, Djibouti, Azerbaiján y Bangladesh. Durante el curso de esta epizootia, que es la más larga que se haya registrado a la fecha, se han producido 385 casos con 243 muertes lo que representa una letalidad del $63 \%$ (figura 2). En la mayoría de ellos la transmisión ha sido por contacto directo con aves enfermas. Sin embargo, se han documentado casos de transmisión persona-persona del virus H5N1. Estos casos de transmisión persona a persona han ocurrido en forma aislada en Tailandia, Indonesia y China siendo aún el contacto con aves enfermas el principal mecanismo de contagio.

Los casos han afectado principalmente a población joven con una edad promedio de 18 


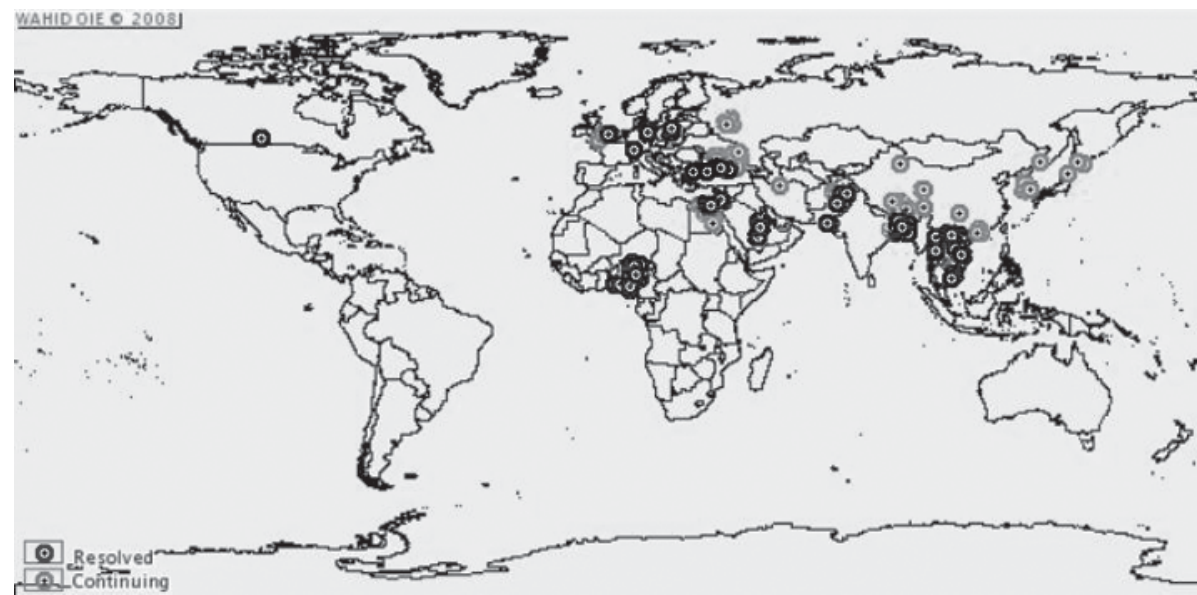

Figura 1. Países afectados por brotes de Influenza Aviar H5N1 en aves 2002-2008. En negro brotes resueltos, en gris brotes activos a la fecha. Fuente OIE.

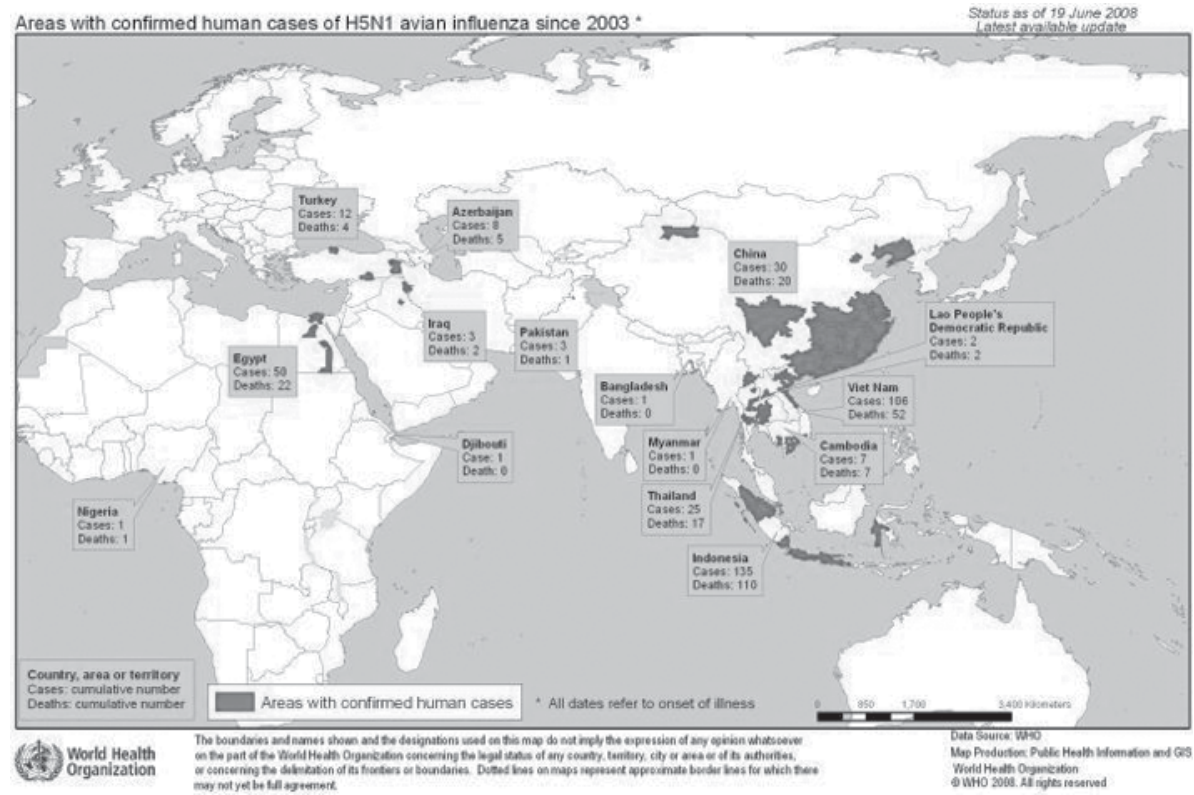

Figura 2. Casos humanos de Influenza A H5N1 2003-2008, Fuente OMS.

años siendo el 90\% menor de 40 años. La mortalidad se ha concentrado en los niños entre los 10 y 19 años. La influenza aviar en humanos se caracteriza por tener un corto período de incubación, generalmente entre 2 a 7 días aunque ocasionalmente hasta 9 días ${ }^{11}$ y una rápida progresión del compromiso de las vías respiratorias desde la aparición de los primeros síntomas. La forma de presentación más frecuente es la neumonía que progresa rápidamente hacia un síndrome de distress respiratorio. La mediana de aparición de neumonía es 4 días desde el inicio de la sintomatología y de 9 días para el evento muerte. Entre los síntomas descritos en influenza aviar en humanos se encuentran la fiebre, tos, coriza, disnea, vómitos y diarrea. En los exámenes de laboratorio destaca la presencia de leucopenia, linfopenia, leve disminución del recuento plaquetario y elevación de transaminasas.

El tratamiento consiste en hospitalización con medidas de aislamiento aéreo considerando el uso de mascarillas de alta eficiencia N95 y soporte en cuidado intensivo. El tratamiento específico con antivirales del tipo de inhibidores de la neuroaminidasa como Oseltamivir ha de- 
mostrado ser eficaz si se utiliza precozmente en el curso de la enfermedad. En una de las variantes genéticas del virus $\mathrm{H} 5 \mathrm{~N} 1$ se ha observado un cierto grado de resistencia a este medicamento por lo que la dosis recomendada y la duración de la terapia es el doble comparado con lo requerido para la influenza estacional. Zanamivir, otro inhibidor de la neuroaminidasa de administración por vía inhalatoria, no ha sido evaluado en influenza aviar pero estudios in vitro demuestran que el virus es susceptible a este medicamento, incluso aquellas variantes resistentes al oseltamivir ${ }^{12}$. El tipo $\mathrm{H} 5 \mathrm{~N} 1$ es frecuentemente resistente a los adamantanos por lo que no se recomienda su utilización.

\section{Condiciones para que se produzca una pandemia}

La emergencia del virus de influenza A H5N1 y cada infección humana por este virus, constituye una oportunidad para que se produzca la modificación genética necesaria para que adquiera la capacidad de reconocer y unirse a receptores específicos presentes en las células de la mucosa nasofaríngea y transmitirse eficientemente para producir enfermedad entre los seres humanos. Sólo cuando se produzca la generación de la cepa pandémica, se podrá conocer la severidad del cuadro clínico y la tasa de ataque con la que afecte a la humanidad.

\section{Preparación para una pandemia}

La amenaza de una Pandemia está siempre presente pero no se puede predecir cuando y donde ocurrirá, sin embargo, el actual escenario internacional aumenta esta probabilidad. Es por ello que es indispensable contar con planes nacionales e internacionales de preparación, flexibles y capaces de producir acciones rápidas y coordinadas que permitan reducir el impacto en morbilidad, mortalidad y desorden social.

Nuestro país en repuesta a esta situación, el año 2003 crea la Comisión Nacional de Respuesta a Brotes y Emergencias Sanitarias a nivel del Ministerio de Salud que tuvo como tarea desarrollar el actual Plan Nacional y que integra acciones desde la vigilancia de influenza en animales a cargo del Servicio Agrícola y Ganadero, la respuesta de la red asistencial y su abastecimiento, incluido farmacia, recursos humanos y el manejo de cadáveres cuando corresponda, control de infecciones para implementar medidas que reduzcan el riesgo de transmisión de la enfermedad en los centros asistenciales, refuerzo de la vigilancia epidemiológica y la coordinación de las acciones de investigación y control de brotes, el diseño de medidas de control comunitario en recintos cerrados y lugares públicos, incluidas las medidas de control de viajeros nacionales e internacionales y un plan de comunicaciones para coordinar la estrategia comunicacional y ejecutar las acciones de información a la comunidad general y públicos específicos. El plan además define las acciones a desarrollar en cada uno de los períodos o etapas de la pandemia y los responsables de llevarlas a cabo.

\section{Vacunas contra influenza pandémica}

Entre las intervenciones específicas que podrían reducir el impacto y la severidad de una pandemia de influenza, están las drogas antivirales y el uso de vacuna.

Las vacunas son una de las herramientas centrales en la prevención de la enfermedad y el objetivo principal es generar anticuerpos contra la hemaglutinina.

La vacuna pandémica más efectiva será aquella basada exactamente en la cepa viral que circule por lo que las características antigénicas específicas sólo podrán definirse en el momento de su circulación.

La población susceptible a la nueva cepa no será la misma que para la influenza estacional lo que plantea un reto para planificar y definir los grupos más vulnerables en quienes iniciar la vacunación durante los brotes iniciales.

En vacuna contra influenza lo que sabemos es que el nivel de anticuerpos contra la $\mathrm{H}$ es crítico para obtener una adecuada protección y que la respuesta es específica para cada cepa. La inmunidad celular es crítica para lograr un adecuado clearance viral.

Por otra parte, se conocen la limitaciones de las vacunas contra influenza estacional, entre ellas la necesidad de dos dosis en niños que son vacunados por primera vez, eficacia reducida en adultos mayores e inmunodeprimidos, capacidad de producción actual limitada a alrededor de 350 millones de dosis en el mundo y la 
necesidad de 6 meses para su manufacturación, lo que ha hecho necesario diseñar vacunas más eficaces y evaluar mejores estrategias de producción, entre las que se encuentran la producción en líneas celulares y genética reversa, el desarrollo de vacunas vivas atenuadas y el uso adyuvantes que permitan reducir la concentración necesaria de antígeno.

Entre las estrategias actuales en preparación de pandemia está el desarrollo de vacunas pre-pandémicas ${ }^{13}$ que sean capaces de generar adecuada respuesta inmune aunque el virus vacuna no sea exactamente el mismo virus que circule al momento de la pandemia. Modelos matemáticos han demostrado que una vacuna con una eficacia del $20 \%$ aplicada a toda la población y asociada a otras medidas de contención podría reducir el impacto en morbilidad y mortalidad comparables a lo que ocurre en brotes epidémicos de influenza estacional ${ }^{14}$. Estas vacunas, actualmente en desarrollo, pueden ser utilizadas en fases previas a la instalación de la pandemia protegiendo parcialmente a la población en espera del desarrollo de una vacuna con la cepa pandémica.

\section{Conclusión}

La aparición de la cepa $\mathrm{H} 5 \mathrm{~N} 1$ con la amenaza de la generación de una pandemia de influenza ha puesto en evidencia la necesidad de desarrollar estrategias de control en diferentes áreas, tales como el desarrollo de nuevas vacunas con nuevas metodologías de producción, desarrollo de antivirales e la intensificación de medidas de control de transmisión entre las personas.

\section{Referencias}

1.- Oxford JS, Sefton A, Jackson R, Innes W, Daniels RS, Johson NPAS: World War I may have allowed the emergence of "Spanish " influenza. Lancet Infect Dis 2002; 2: 111-4

2.- Sarubbi F: Influenza. A historical perspective. South Med J 2003; 96. 735-6.

3.- Moorman J: Viral characteristics of Influenza. South Med J 2003; 96; 758-61.

4.- Zambon M: The pathogenesis of Influenza in humans. Rev Med Virol 2001; 11: 227-41.

5.- Webster $R G$, Hulse DJ. Microbial adaptation and change: avian influenza. Rev Sci Tech Off Int Epiz, 2004;23: 453-65

6.- Belshe R: The origin of pandemic influenza-Lessons from the 1918 virus. N Engl J Med 2005; 353: 220911 .

7.- Ungshusak K, Auewarakul P, Dowell S, et al: Probable person-to-person transmission of avian influenza A (H5N1). N Engl J Med 2005; 352: 333-40.

8.- Trampuz A, Prabhu R, Smith T, Baddour L: Avian influenza. A new pandemic threat. Mayo Clin Proc 2004; 79: 523-30

9.- Fouchier R, Osterhaus A, Brown I: Animal influenza virus surveillance. Vaccine 2003; 21: 1754-7.

10.- Suárez D, Senne D, Banks J: Recombination Resulting in Virulence Shift in Avian Influenza Outbreak, Chile. Emerg Infect Dis 2004; 10 (4): 693-9.

11.- Writing committee of the second world health organization consultation on clinical aspects of human infection with avian influenza A (H5NI) virus. Update on Avian Influenza A (H5N1) virus infection in humans. N Engl J Med 2008; 358: 261

12.- Le QM, Kiso $M$, Someya $K$, et al: Avian flu: Isolation of drug- resistant H5N1 virus. Nature 2005; 437: 1108.

13.- Wright $P$. Vaccine Preparedness. Are we ready for the next Influenza pandemic? N Engl J Med 2008; 358: 2540-3.

14.- Department of Health, UK: Pre-Pandemic and Pandemic Influenza Vaccines. En United Kindom, Department of Health website. Http://www.dh.gov.uk/ en/Publicationsandstatistics/Publications/publicationspolicyandguidance/DH_077276, último acceso el 1 de agosto 2008 . 